\title{
The PRONTO study: Clinical performance of ID NOW in individuals with compatible SARS-CoV-2 symptoms in walk-in centres- accelerated turnaround time for contact tracing
}

Isabelle Goupil-Sormany 1,2, Jean Longtinn,4, Jeannot Dumaresq 4,5, Marieve Jacob-Wagner ${ }^{3}$, Frédéric Bouchard ${ }^{6}$, Liliana Romero ${ }^{7}$, Julie Harvey ${ }^{8}$, Julie Bestman-Smith ${ }^{3,4}$, Mathieu Provençal ${ }^{9}$, Stéphanie Beauchemin, Valérie Richard², Annie-Claude Labbé9,10,11*

\section{Abstract \\ Background: This PRONTO study investigated the clinical performance of the Abbott ID NOW'M (IDN) COVID-19 diagnostic assay used at point of care and its impact on turnaround time for divulgation of test results. \\ Methods: Prospective study conducted from December 2020 to February 2021 in acute symptomatic participants presenting in three walk-in centres in the province of Québec.}

Results: Valid paired samples were obtained from 2,372 participants. A positive result on either the IDN or the standard-of-care nucleic acid amplification test (SOC-NAAT) was obtained in 423 participants (prevalence of $17.8 \%$ ). Overall sensitivity of IDN and SOC-NAAT were $96.4 \%$ (95\% Cl: 94.2-98.0\%) and 99.1\% (95\% Cl: 97.6-99.8), respectively; negative predictive values were $99.2 \%$ (95\% Cl: 98.7-99.6\%) and 99.8\% (95\% Cl: 99.5-100\%), respectively. Turnaround time for positive results was significantly faster on IDN.

Conclusion: In our experience, IDN use in symptomatic individuals in walk-in centres is a reliable sensitive alternative to SOC-NAAT without the need for subsequent confirmation of negative results. Such deployment can accelerate contact tracing, reduce the burden on laboratories and increase access to testing.

Suggested citation: Goupil-Sormany I, Longtin J, Dumaresq J, Jacob-Wagner M, Bouchard F, Romero L, Harvey J, Bestman-Smith J, Provençal M, Beauchemin S, Richard V, Labbé A-C. The PRONTO study: Clinical performance of ID NOW in individuals with compatible SARS-CoV-2 symptoms in walk-in centres-accelerated turnaround time for contact tracing. Can Commun Dis Rep 2021;47(12):534-42. https://doi.org/10.14745/ccdr.v47i12a04

Keywords: COVID-19, SARS-CoV-2, nucleic acid amplification tests, rapid tests, Abbott ID NOW, sensitivity and specificity, predictive value, diagnostic performance, point-of-care testing, Canada

\section{Introduction}

Currently, the most reliable methodologies for coronavirus disease 2019 (COVID-19) testing are standard laboratory-based nucleic acid amplification tests (NAAT). However, over the first waves of the pandemic, reagent shortages and high demand have challenged our public health capacity and reactivity (1-4). The long turnaround time (TAT) required to produce a test result has also compromised search and contact tracing strategies (5-7). Stand alone rapid tests in specific settings are expected to accelerate case and contact tracing, along with improving public health actions (8-10).
This work is licensed under a Creative Commons Attribution 4.0 International License.

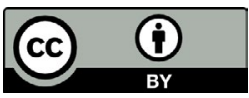

Affiliations

1 Direction de la vigie sanitaire, Ministère de la Santé et des Services sociaux du Québec, QC

${ }^{2}$ Département de médecine sociale et préventive, Faculté de Médecine, Université Laval, Québec, QC

${ }^{3}$ Département de microbiologie et d'infectiologie du centre hospitalier universitaire (CHU) de Québec -

Université Laval, Québec, OC

${ }^{4}$ Département de

microbiologie-infectiologie et d'immunologie, Faculté de

Médecine, Université Laval,

Québec, QC

${ }^{5}$ Département de microbiologie et d'infectiologie, CISSS de

Chaudière-Appalaches, Lévis, QC

${ }^{6}$ Laboratoire de biochimie

médicale, CISSS de

Chaudière-Appalaches, Lévis, QC

Direction de la Santé publique, CISSS de Chaudière-Appalaches, Lévis, QC

${ }^{8}$ Direction de la Santé publique, CIUSSS de la Capitale-Nationale, Québec, QC

${ }^{9}$ Département des laboratoires de biologie médicale, Grappe Optilab-CHUM, Centre hospitalier de l'Université de Montréal, Montréal, QC

${ }^{10}$ Département de microbiologie, infectiologie et immunologie, Université de Montréal, Montréal, QC

${ }^{11}$ Service de maladies infectieuses Hôpital Maisonneuve-Rosemont, CIUSSS de l'Est-de-l'île-de-Montréal, Montréal, QC

*Correspondence:

ac.labbe@umontreal.ca
The Abbott ID NOW'M (IDN) COVID-19 assay, an isothermal NAAT targeting a RdRp segment of severe acute respiratory syndrome coronavirus 2 (SARS-CoV-2), was granted Health Canada emergency use authorization on September 30, 2020. It is authorized as a lab-based and 
point-of-care diagnostic assay for the detection of SARS-CoV-2 in individuals with COVID-19 symptoms for fewer than or equal to seven days at time of testing. Early published studies established a lower analytical sensitivity compared with many laboratory-based NAAT assays (11-15). According to the product insert, negative results are to be treated as presumptive and be confirmed with a cleared NAAT. The Canadian Public Health Laboratory Network and the Canadian Society of Clinical Chemist subsequently recommended certain clinical use scenarios to balance expected limited sensitivity with other considerations (16).

Published literature demonstrated that the clinical sensitivity of IDN was linked to corresponding viral loads, with false negative results tending to occur when the standard laboratory-based NAAT cycle thresholds $(\mathrm{Ct})$ are 32 or higher, reflecting lower viral loads $(12,13,17)$. As shown by others, the highest viral loads were found in symptomatic participants presenting in community walk-in centres (9-11). The present study aimed to assess whether IDN could be used as a reliable stand-alone test (without subsequent confirmation) as a means to intervene more quickly on transmission chains, relieve laboratory human and material resources and give more autonomy to front-line healthcare providers. As such, we are reporting the agreement and clinical performance of the IDN, compared to a standardof-care NAAT (SOC-NAAT) assay, among prospectively recruited symptomatic individuals presenting in community walk-in centres in the province of Québec, Canada.

\section{Methods}

In December 2020, IDN instruments were implemented in three walk-in centres in the province of Québec. Volunteer participants were asked to confirm that symptom onset was fewer than or equal to seven days prior to testing and to provide two samples simultaneously, as detailed in Table 1.

The oropharyngeal and bilateral nasal swab (OBNS) for the IDN assay was collected with the foam swab provided with the Abbott ID NOW COVID-19 kit as follows: after swabbing the posterior pharynx, tonsils and other inflamed areas for a few seconds each, the swab was inserted in one nostril until a resistance was met at the level of the turbinates (approximatively $2 \mathrm{~cm}$ ), rotated five times against the nasal wall and slowly removed from the nostril; the same swab was then used for the other nostril. The OBNS for IDN was collected after the oral and nasopharyngeal swab (ONPS) for SOC-NAAT in Québec City and Montréal (18), but performed prior to the gargle for SOC-NAAT in Lévis (19), since the gargle procedure could dilute any virus present when swabbing for IDN.

The IDN test was performed on-site, within one hour of collection, by professionals from diverse training and experience backgrounds who were trained by our teams on using the IDN instrument as per the package insert.
Table 1: Characteristics of the participating centres: Type of clinic, sampling and testing methodologies

\begin{tabular}{|l|l|l|}
\hline \multicolumn{1}{|c|}{ Characteristics } & \multicolumn{1}{|c|}{$\begin{array}{c}\text { Québec City } \\
\text { and Montréal }\end{array}$} & \multicolumn{1}{c|}{ Lévis } \\
\hline Type of centre & Walk-in clinic & Drive-thru clinic ${ }^{\mathrm{a}}$ \\
\hline $\begin{array}{l}\text { SOC-NAAT } \\
\text { sampling }\end{array}$ & ONPS & $\begin{array}{l}\text { Gargle } \\
\text { ONPS (when gargle } \\
\text { not feasible) }\end{array}$ \\
\hline $\begin{array}{l}\text { SOC-NAAT } \\
\text { method }\end{array}$ & $\begin{array}{l}\text { Laboratory-developed } \\
\text { PCR }\end{array}$ & $\begin{array}{l}\text { Allplex } \\
\text { (Seegene) direct PCR }\end{array}$ \\
\hline $\begin{array}{l}\text { Sampling } \\
\text { sequence }\end{array}$ & $\begin{array}{l}\text { SOC-NAAT followed by } \\
\text { IDN }\end{array}$ & $\begin{array}{l}\text { IDN followed by } \\
\text { SOC-NAAT }\end{array}$ \\
\hline IDN sampling & OBNS & OBNS \\
\hline Abbreviations: IDN, ID NOWTM. OBNS, oropharyngeal and bilateral nasal swab; ONPS, oral and
\end{tabular}

Abbreviations: IDN, ID NOW'TM; OBNS, oropharyngeal and bilateral nasal swab; ONPS, oral and nasopharyngeal swab; PCR, polymerase chain reaction; SOC-NAAT, standard of care-nucleic acid amplification testing

a For text simplification, all three centres were considered as walk-in clinics

The SOC-NAAT in Montréal (Hôpital Maisonneuve-Rosemont; HMR) and Québec City (CHU de Québec) was a real-time polymerase chain reaction $(\mathrm{PCR})$ assay targeting the structural protein envelope $E$ gene $(18,20)$. Inactivation and thermal lysis, rather than chemical extraction, were performed prior to PCR testing, as previously described (18). The SOC-NAAT in Lévis (Centre intégré de santé et de services sociaux [CISSS] de Chaudière-Appalaches) was based on Seegene Allplex ${ }^{\mathrm{TM}}$ technology as previously described (19).

No personal data were collected outside of the information available on the standard COVID-19 laboratory form (gender, age, duration of symptoms, COVID-19 contact history). The duration of symptoms and contact history, combined with supplemental NAAT when applicable, were used to classify infection stages of participants for whom discordant results were obtained. Acute infection was defined as at least having one symptom among fever, cough, runny nose, dyspnea, sore throat, anosmia and ageusia, or a combination of two of the following: headache, fatigue, muscle pain, anorexia, nausea or vomiting, abdominal cramps or diarrhea within seven days of onset. When the collected data revealed misclassification, erroneous data collected by staff or by participant mistake, the case remained included in the study since representing a real-life situation.

For each study site, TAT was defined as the time between sample collection and the availability of the laboratory report for concordantly positive pairs (both the IDN and the SOC-NAAT results were reported). In Lévis, the time between sample collection and completion of public health questionnaire with the case and household contacts was also calculated. The TAT for negative results was not monitored since negative IDN results were not reported during the study period.

This PRONTO study was undertaken in the midst of the second wave of the COVID-19 in Québec, with thousands of samples being received on a daily basis. There was a context of emergency (with public, administrative and media pressure) to implement rapid testing. Formal Ethical Review Board approval 
was lifted since the study was mandated by the directeur national de santé publique as part of the Public Health response during the sanitary emergency state. Explicit verbal consent was obtained from all participants after receiving a verbal description of the project.

\section{Statistical analysis}

Samples producing invalid results in either arm were excluded from the calculations.

Data were analyzed using a contingency table. In the absence of a gold standard for SARS-CoV-2 ribonucleic acid (RNA) detection, the reference method used for positive percent agreement and negative percent agreement was the SOC-NAAT. In addition to computing the overall rates of agreement, the level of agreement was assessed using kappa statistics (STATA V16.1). By definition, kappa values above 0.75 indicate excellent agreement, values between 0.40 and 0.75 indicate fair to good agreement, and values below 0.40 represent poor agreement beyond chance (21). To evaluate the clinical sensitivity and negative predictive value of IDN and SOC-NAAT, a participant was considered infected if at least one result from the paired samples was positive, assuming $100 \%$ specificity of both assays. The $95 \%$ confidence intervals $(95 \% \mathrm{Cl})$ were obtained with STATA V16.1.

\section{Outcomes}

Between December 6 and February 22, 2020, paired samples were obtained from 2,395 individuals. After exclusion of 23 pairs associated with an invalid result with either method, the performance analysis was based on 2,372 participants (Table 2).

Table 2: Participant characteristics and number of valid pairs included $(\mathrm{N}=2,395)$

\begin{tabular}{|c|c|c|c|c|c|c|c|c|}
\hline \multirow{2}{*}{$\begin{array}{c}\text { Participant } \\
\text { characteristics }\end{array}$} & \multicolumn{2}{|c|}{ Québec City } & \multicolumn{2}{|c|}{ Lévis } & \multicolumn{2}{|c|}{ Montréal } & \multicolumn{2}{|c|}{ Total } \\
\hline & $n$ & $\%$ & $n$ & $\%$ & $n$ & $\%$ & $n$ & $\%$ \\
\hline $\begin{array}{l}\text { Symptomatic } \\
\text { participants } \\
\text { recruited }\end{array}$ & 1,246 & $\mathrm{~N} / \mathrm{A}$ & 790 & N/A & 359 & $N / A$ & 2,395 & N/A \\
\hline Invalid results & 12 & 1.0 & 9 & 1.1 & 2 & 0.6 & $23^{a}$ & 1.0 \\
\hline $\begin{array}{l}\text { Valid paired } \\
\text { samples }\end{array}$ & 1,234 & 99.0 & 781 & 98.9 & 357 & 99.4 & 2,372 & 99.0 \\
\hline Male gender & 544 & 44.1 & 370 & 47.4 & 154 & 43.1 & 1,068 & 45.0 \\
\hline Mean age & 40 & N/A & 32 & $\mathrm{~N} / \mathrm{A}$ & 38 & $\mathrm{~N} / \mathrm{A}$ & 37 & $\mathrm{~N} / \mathrm{A}$ \\
\hline $\begin{array}{l}\text { Age range } \\
\text { (years) }\end{array}$ & $1-88$ & N/A & $1-83$ & N/A & $1-80$ & N/A & $1-88$ & $\mathrm{~N} / \mathrm{A}$ \\
\hline $\begin{array}{l}\text { Younger than } 18 \\
\text { years of age }\end{array}$ & 118 & 9.6 & 109 & 14.0 & 33 & 9.2 & 260 & 11.0 \\
\hline
\end{tabular}

As shown in Table 3, a total of 423 participants (17.8\%) were considered infected (at least one positive result by IDN or SOC-NAAT). Positive concordant results were obtained on 404 pairs (95.5\%); among the 19 discordant pairs, four were positive with IDN only and 15 with SOC-NAAT only. Agreement was excellent, as reflected by a kappa coefficient value of 0.97 . Overall, IDN sensitivity and negative predictive value were respectively estimated at $96.4 \%$ (95\% Cl 94.2-98.0) and 99.2\% (95\% Cl 98.7-99.6), with little (not statistically significant) variation across centres (Table 4)

Table 3: Prevalence of SARS-CoV-2 infection and distribution of Abbott ID NOW'TM and standard-of-care nucleic acid amplification test results in symptomatic individuals $(n=2,372)$

\begin{tabular}{|c|c|c|c|c|c|}
\hline \multirow{3}{*}{ Location } & \multicolumn{2}{|c|}{ Prevalence $^{a}$} & \multicolumn{3}{|c|}{ Results } \\
\hline & \multirow{2}{*}{$n / N$} & \multirow{2}{*}{$\%$} & \multirow{2}{*}{ IDN } & \multicolumn{2}{|c|}{ SOC-NAAT } \\
\hline & & & & POS & NEG \\
\hline \multirow{2}{*}{$\begin{array}{l}\text { Québec } \\
\text { City }\end{array}$} & \multirow{2}{*}{$193 / 1,234$} & \multirow{2}{*}{15.6} & POS & 187 & 2 \\
\hline & & & NEG & 4 & 1,041 \\
\hline \multirow{2}{*}{ Lévis } & \multirow{2}{*}{$114 / 781$} & \multirow{2}{*}{14.6} & POS & 109 & 1 \\
\hline & & & NEG & 4 & 667 \\
\hline \multirow{2}{*}{ Montréal } & \multirow{2}{*}{$116 / 357$} & \multirow{2}{*}{32.5} & POS & 108 & 1 \\
\hline & & & NEG & 7 & 241 \\
\hline \multirow{2}{*}{ Total } & \multirow{2}{*}{$423 / 2,372$} & \multirow{2}{*}{17.8} & POS & 404 & 4 \\
\hline & & & NEG & 15 & 1,949 \\
\hline
\end{tabular}

Abbreviations: IDN, ID NOW' ${ }^{\mathrm{M}}$; NEG, negative; POS, positive; SOC-NAAT, standard of care-nucleic acid amplification testing

a A participant was considered infected if at least one result from the paired samples was positive, assuming $100 \%$ specificity of IDN and SOC-NAAT

Characteristics of the 19 participants for whom discordant results were obtained are presented in Table 5. For the 15 negative IDN, the mean $\mathrm{Ct}$ value of the corresponding positive SOC-NAAT was 33.5 (range 30.9-35.0). The mean $\mathrm{Ct}$ values for the concordantly positive pairs, available for the Québec City site (26.0) and the Montréal site (23.5), were clearly lower, reflecting a higher viral load. Among the 15 participants for whom the discordant profile was SOC-NAAT positive/IDN negative, two were asymptomatic, four were considered as late presentation and nine as acutely infected. Among the four participants for whom the discordant profile was SOC-NAAT negative/IDN positive, two had an acute infection and two could not be staged nor confirmed by supplementary testing.

The TAT between sampling and availability of laboratory report of positive results was on average 20.1 hours for SOC-NAAT and 1.2 hours for IDN. In Lévis, TAT between sampling and end of public health tracing was on average 36.0 hours for the symptomatic individuals who either had SOC-NAAT positive/ IDN negative results or did not participate in this study but were assessed at the same drive-through clinic during the same period, and for whom testing was performed by SOC-NAAT 
Table 4: Agreement between Abbott ID NOW'M and standard-of-care nucleic acid amplification testing results and clinical performance $(n=2,372)$

\begin{tabular}{|c|c|c|c|c|c|}
\hline \multirow{2}{*}{ Test } & \multirow{2}{*}{ Statistics } & \multicolumn{4}{|c|}{ Assessment center } \\
\hline & & Québec City & Lévis & Montréal & Total \\
\hline \multicolumn{6}{|l|}{ Agreement } \\
\hline \multirow{2}{*}{$\mathrm{PPA}^{\mathrm{a}}$} & $\%$ & 98.9 & 99.1 & 99.1 & 99.0 \\
\hline & $95 \% \mathrm{Cl}$ & $96.2-99.9$ & $95.0-100$ & $95.0-100$ & $97.5-99.7$ \\
\hline \multirow{2}{*}{ NPA $^{a}$} & $\%$ & 99.6 & 99.4 & 97.2 & 99.2 \\
\hline & $95 \% \mathrm{Cl}$ & $99.0-100$ & $98.5-99.8$ & $94.3-98.9$ & $98.7-99.6$ \\
\hline \multirow{2}{*}{ ORA } & $\%$ & 99.5 & 99.4 & 97.8 & 99.2 \\
\hline & $95 \% \mathrm{Cl}$ & $98.9-99.8$ & $98.5-99.8$ & $95.6-99.0$ & $98.8-99.5$ \\
\hline \multirow{2}{*}{ Cohen's kappa } & $K$ & 0.98 & 0.97 & 0.95 & 0.97 \\
\hline & $95 \% \mathrm{Cl}$ & $0.97-1.00$ & $0.95-1.00$ & $0.91-0.98$ & $0.96-0.98$ \\
\hline \multicolumn{6}{|c|}{ Clinical performance ${ }^{b}$} \\
\hline \multirow{2}{*}{ IDN sensitivity } & $\%$ & 97.9 & 96.5 & 94.0 & 96.4 \\
\hline & $95 \% \mathrm{Cl}$ & $94.8-99.4$ & $91.3-99.0$ & $88.0-97.5$ & $94.2-98.0$ \\
\hline \multirow{2}{*}{ SOC-NAAT sensitivity } & $\%$ & 99.0 & 99.1 & 99.1 & 99.1 \\
\hline & $95 \% \mathrm{Cl}$ & $96.3-99.9$ & $95.2-100$ & $95.3-100$ & $97.6-99.7$ \\
\hline \multirow{2}{*}{ IDN NPV } & $\%$ & 99.6 & 99.4 & 97.1 & 99.2 \\
\hline & $95 \% \mathrm{Cl}$ & $99.0-99.9$ & $98.5-99.8$ & $94.1-98.8$ & $98.7-99.6$ \\
\hline \multirow{2}{*}{ SOC-NAAT NPV } & $\%$ & 99.8 & 99.9 & 99.6 & 99.8 \\
\hline & $95 \% \mathrm{Cl}$ & $99.3-100$ & $99.2-100$ & $97.7-100$ & $99.5-100$ \\
\hline
\end{tabular}

Abbreviations: $\mathrm{Cl}$, Confidence Interval; IDN, ID NOW'TM; NPA, negative percent agreement; NPV, negative predictive value; ORA, overall rates of agreement; PPA, positive percent agreement; SOC-NAAT, standard of care-nucleic acid amplification test

aPA and NPA were computed by considering the SOC-NAAT as the reference method

${ }^{b}$ A participant was considered infected if at least one result from the paired samples was positive, assuming $100 \%$ specificity of IDN and SOC-NAAT

Table 5: Laboratory and clinical information of participants in whom discrepant results were obtained $(n=19)$

\begin{tabular}{|c|c|c|c|c|c|}
\hline $\begin{array}{l}\text { Assessment } \\
\text { center }\end{array}$ & $\begin{array}{c}\text { SOC-NAAT } \\
\text { Ct value }\end{array}$ & $\begin{array}{l}\text { Symptoms } \\
\text { duration }^{\mathrm{b}, \mathrm{c}}\end{array}$ & $\begin{array}{l}\text { Contact with } \\
\text { a known } \\
\text { case }^{\mathrm{b}}\end{array}$ & Supplementary testing ${ }^{d}$ & Clinical stage \\
\hline
\end{tabular}

IDN negative and SOC-NAAT positive (IDN false negative), $\mathrm{n}=15$

\begin{tabular}{|c|c|c|c|c|c|}
\hline \multirow{4}{*}{ Québec City } & 34.2 & $\begin{array}{l}\text { Symptoms } \\
\text { resolved } 6 \text { days } \\
\text { earlier }\end{array}$ & Unknown & $\begin{array}{l}\text { Initial SOC-NAAT sample retested after chemical } \\
\text { extraction: positive result with Ct value of } 33.4 \\
\text { Resampled } 72 \text { hours later and tested by IDN and } \\
\text { SOC-NAAT with a Ct value of } 35\end{array}$ & $\begin{array}{l}\text { Late presentatione } \\
\text { (post-symptomatic) }\end{array}$ \\
\hline & 34.8 & $\mathrm{~N} / \mathrm{A}$ & $\begin{array}{l}\text { Yes, but not } \\
\text { detailed }\end{array}$ & $\begin{array}{l}\text { Initial SOC-NAAT sample retested after chemical } \\
\text { extraction: positive result with Ct value of } 32.4\end{array}$ & Asymptomatic \\
\hline & 34.0 & $\begin{array}{l}\text { Less than } 24 \\
\text { hours }\end{array}$ & Unknown & $\begin{array}{l}\text { Initial SOC-NAAT sample retested after chemical } \\
\text { extraction: positive result with Ct value of } 32.9\end{array}$ & Acute presentation \\
\hline & 31.5 & More than 7 days & Unknown & ND & Late presentation ${ }^{\mathrm{e}}$ \\
\hline \multirow{4}{*}{ Lévis } & $\begin{array}{l}34.0 \\
\text { ( } 2 / 3 \text { genes) }\end{array}$ & $\mathrm{N} / \mathrm{A}$ & $\begin{array}{l}\text { Yes, but not } \\
\text { detailed }\end{array}$ & $\begin{array}{l}\text { Resampled } 2 \text { days later: negative on IDN and SOC- } \\
\text { NAAT } \\
\text { IDN swab }{ }^{f} \text { retested by two other assays }{ }^{f} \text { negative } \\
\text { results }\end{array}$ & Asymptomatic \\
\hline & $\begin{array}{l}32.0 \\
(3 / 3 \text { genes })\end{array}$ & 2 days & Home & ND & Acute presentation \\
\hline & $\begin{array}{l}30.9 \\
\text { (3/3 genes) }\end{array}$ & 1 day & Workplace & $\begin{array}{l}\text { IDN swabf retested by two other assays: weakly } \\
\text { positive with one assay }\end{array}$ & Acute presentation \\
\hline & $\begin{array}{l}34.4 \\
(3 / 3 \text { genes })\end{array}$ & 1 day & Home & $\begin{array}{l}\text { IDN swabf retested by two other assays }{ }^{g} \text { : weakly } \\
\text { positive with one assay }\end{array}$ & Acute presentation \\
\hline
\end{tabular}


Table 5: Laboratory and clinical information of participants in whom discrepant results were obtained $(n=19)$ (continued)

\begin{tabular}{|c|c|c|c|c|c|}
\hline $\begin{array}{l}\text { Assessment } \\
\text { center }\end{array}$ & $\begin{array}{c}\text { SOC-NAATa } \\
\text { Ct value }\end{array}$ & $\begin{array}{l}\text { Symptoms } \\
\text { duration }^{b, c}\end{array}$ & $\begin{array}{l}\text { Contact with } \\
\text { a known } \\
\text { case }^{b}\end{array}$ & Supplementary testing ${ }^{d}$ & Clinical stage \\
\hline
\end{tabular}

IDN negative and SOC-NAAT positive (IDN false negative), $\mathrm{n}=15$ (continued)

\begin{tabular}{|c|c|c|c|c|c|}
\hline \multirow{7}{*}{ Montréal } & 34.2 & More than 7 days & Home & ND & Late presentation \\
\hline & 33.5 & 1 day & Workplace & ND & Acute presentation \\
\hline & 31.6 & 3 days & Home & ND & Acute presentation \\
\hline & 35.0 & 7 days & Unknown & ND & Late presentation \\
\hline & 34.2 & 2 days & No & ND & Acute presentation \\
\hline & 34.9 & 4 days & Unknown & ND & Acute presentation \\
\hline & 33.3 & $\begin{array}{l}\text { Less than } 24 \\
\text { hours }\end{array}$ & School & $\begin{array}{l}\text { Initial SOC-NAAT sample retested after chemical } \\
\text { extraction: positive with Ct value of } 33.7\end{array}$ & Acute presentation \\
\hline
\end{tabular}

IDN positive and SOC-NAAT negative (SOC-NAAT false negative), $n=4$

\begin{tabular}{|c|c|c|c|c|c|}
\hline \multirow{2}{*}{ Québec City } & \multirow{4}{*}{ N/A } & 2 hours & School & $\begin{array}{l}\text { IDN swab tested by NAAT after chemical extraction: } \\
\text { positive result with a Ct value of } 25.5 \\
\text { Initial SOC-NAAT sample retested after chemical } \\
\text { extraction: positive result with a Ct value of } 33.8\end{array}$ & Acute presentation \\
\hline & & Unknown & Unknown & $\begin{array}{l}\text { IDN swab tested by NAAT after chemical extraction: } \\
\text { positive result with a Ct value of } 30.8 \\
\text { Initial SOC-NAAT sample retested after chemical } \\
\text { extraction: positive result with a } \mathrm{Ct} \text { value of } 35.2\end{array}$ & Unknown \\
\hline Lévis & & 1 day & Unknown & $\begin{array}{l}\text { IDN swabf tested by two other assays: negative } \\
\text { results } \\
\text { Initial SOC-NAAT sample retested by two commercial } \\
\text { assays }{ }^{g} \text { : negative results }\end{array}$ & $\begin{array}{l}\text { Acute } \\
\text { presentation; } \\
\text { possible false- } \\
\text { positive IDN }\end{array}$ \\
\hline Montréal & & 5 days & Home & ND & $\begin{array}{l}\text { Acute presentation } \\
\text { vs. possible false- } \\
\text { positive IDN }\end{array}$ \\
\hline
\end{tabular}

Abbreviations: $\mathrm{Ct}$, cycle threshold; IDN, ID NOW'TM; N/A, not applicable; ND, not done; SOC-NAAT, standard of care-nucleic acid amplification test

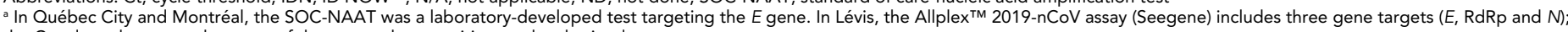
the $\mathrm{Ct}$ values shown are the mean of the two or three positive results obtained

${ }^{b}$ The duration of symptoms before testing and COVID-19 contact history were obtained through the standard routine questionnaire form. Missing information occurs frequently

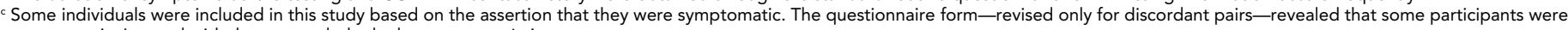
asymptomatic. It was decided not to exclude the latter a posteriori

d The alternate NAAT was the laboratory-developed test preceded by chemical RNA extraction using the NucliSens easyMAG platform (bioMérieux; Saint-Laurent, Canada)

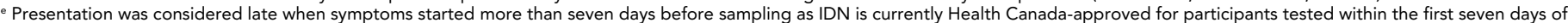
symptoms

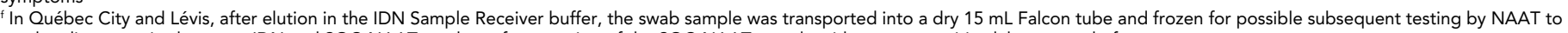
resolve discrepancies between IDN and SOC-NAAT results or for retesting of the SOC-NAAT sample with a more sensitive laboratory platform

g Simplexa COVID-19 (DiaSorin) and FilmArray RP 2.0 (bioMérieux)

( $n=283)$; it was 13.6 hours for the 110 participants for whom the IDN was positive, representing a difference of 22.4 hours $(95 \% \mathrm{Cl}$ 18.8-26.1, $p<0.0001)$.

\section{Discussion}

In this PRONTO study, the clinical performance of IDN was compared to SOC-NAAT among a large number of symptomatic individuals in community-based walk-in centres. Agreement between the two testing strategies was nearly perfect. Although the sensitivity of IDN (96.4\%) was slightly lower than for SOC-NAAT (99.1\%), the difference was not statistically significant. Very few false negative results were observed in both arms, resulting in excellent negative predictive value of 99.5\% and $99.8 \%$ for IDN and SOC-NAAT, respectively. Thus, our results differ from earlier studies that demonstrated lower sensitivity $(55 \%-84 \%)(22,23)$. Some recent studies suggest a better performance (86\%-100\%), although the $95 \% \mathrm{Cl}$ in these latter studies were wider, due to a smaller sample size (22-28). This discrepancy in sensitivity might be explained by variation in pre-test probability in the target population (29) and by our optimized swabbing methodology (30). The current study was performed in a group with probable higher viral titers and higher pre-test probability, during a high prevalence wave. A multi-compartment swabbing protocol was also used herein, which included three throat areas and both nostrils, which has been previously shown to be a sensitive alternative to nasopharyngeal swabbing (31). Another possible explanation is that the SOC-NAAT comparators used in our study are associated with lower analytical sensitivity than other commercial NAATs currently used for the detection of SARS-CoV-2 (18). 
Indeed, at the Montréal site (data not shown), during the same period, 127 similar individuals (with COVID-19 compatible symptoms) had their ONPS tested by a commercial NAAT: 38 had concordant positive results; 85 had concordant negative results; and four had negative IDN but positive commercial NAAT results (sensitivity of the IDN 90.5\%; 95\% Cl 77.4-97.3).

The discrepant pairs were classified according to their probable clinical stage since later infections with higher $\mathrm{Ct}$ values might not represent contagiousness (32-34). We presumed, as a hypothesis for our study, that false negative results would be associated with a lower viral load, with the infected individual being less infectious. Although the timing of the test is important to monitor dynamic viral load, our data confirmed discordant results to be associated with higher $\mathrm{Ct}$, an indirect indicator of viral load $(35,36)$.

The risk of not detecting all cases (or risk of false negative results) can be mitigated by appropriate counselling: automated messages sent with negative results invite people to get retested and seek medical attention if symptoms do not resolve by themselves after 48 hours $(37,38)$. It could also be counterbalanced by the timeliness of the results and the possibility of increasing access to testing by increasing overall laboratory capacity. Although lower IDN sensitivity and missed cases could be deemed obstacles for promoting the technology, we believe otherwise, especially in the context of high vaccination uptake. Clinical sensitivity of a strategy should include analytical sensitivity but also TAT and access to testing. IDN use accelerated contact tracing, and we feel it increased access to testing by offering a less intrusive OBNS sampling and by delocalizing to the point-of-care. In fact, a Québec survey poll showed that half of the eligible population with COVID-19 compatible symptoms did not get tested during the study period (39). Rapid testing or more comfortable sampling methods could represent a valuable solution $(18,19)$.

The optimal approach for the diagnosis of COVID-19 remains under debate. Some experts focus on test sensitivity and neglect the public health and population impacts of accelerated contact tracing $(7,8)$. Although SOC-NAAT processes are now optimised for high testing volume, laboratory resources are profoundly stretched, particularly with the return to "normal" of healthcare activities. An attractive scenario would be to supply IDN directly to first-line clinics, with clear guidance on whom to test with this strategy (for example, symptomatic individuals and close contacts of positive cases). Cost-effective analysis should be undertaken to better guide Canadian public health specialists, microbiologists, administrators and clinicians.

In our study, results were available faster if samples were tested with IDN vs. SOC-NAAT in all assessment centres, with a faster public health inquiry in Lévis for IDN compared to SOC-NAAT. Although representing different indicators, both are proxies for public health intervention, and congruent in showing a net advantage for IDN. Current public health recommendations are that people with COVID-19 symptoms (and their household contacts in certain high-prevalence regions) should self-isolate from the onset of symptoms. However, no interventions have been made to possible contacts until symptomatic participants have a confirmed diagnosis of COVID-19. Without rapid results, public health loses a valuable window of opportunity, particularly if these contacts do not express a typical disease presentation. We can also postulate that adherence to self-isolation is increased when the diagnosis is confirmed.

\section{Strengths and limitations}

Among all the similar studies published to date, this PRONTO study has the largest number of participants, even exceeding the total number of participants included in the systematic review by Tu et al. (24). Being a multi-site study and performed in a real-life setting (e.g. the personnel performing the IDN testing stemmed from diverse training and experience backgrounds), external validity is increased. We were able to collect comparative data as part of the implementation process in overwhelmed walk-in centres and laboratories. We also aimed to document, in two of the sites, the impact of rapid testing on public health. Although a cause-and-effect relationship between IDN use and the impact on transmission to contacts cannot be established, we postulate that faster tracing will benefit public health containment strategies $(9,10)$.

Our study has certain limitations. First, SOC-NAAT differed between laboratories, although adhered to the same validation panels provided by the provincial Public Health Laboratory. Second, very little participant-level data were collected from participating institutions. As such, IDN could not be correlated with the indications for testing, the appropriateness of the test, and the clinical evolution of participants with positive test results. Third, differences in practices within and between walkin centres (for example different personnel, rapidly changing recommendations over time) may represent confounding variables; for example, by including some asymptomatic participants. Fourth, our diagnostic definition (at least one positive result from the paired samples), which implies 100\% specificity of both assays, may have lead to slight overestimation of the sensitivity for both assays. While false positive IDN results are considered unlikely (28) compared with the well described false positive laboratory PCR results (40), we suspect two false positive results in our study (Table 5), and we witnessed some infrequent confirmed false positive IDN results in routine care after the end of the study.

\section{Conclusion}

Based on our large experience, IDN use in walk-in centres with an optimized sampling method in acute symptomatic participants can be achieved safely without the need for laboratory confirmation of negative results. In this context, IDN can be considered a stand-alone testing option. Such deployment 
accelerates contact tracing of positive cases and reduces the burden on laboratories, while increasing access to testing.

\section{Authors' statement}

IGS - Conceived the original idea, acquired the financial support, performed literature searches, drafted the manuscript, review and editing

$\mathrm{JL}$ - Conceived the original idea and statistical analysis, performed initial literature searches, wrote the first draft, supervised the project

JD - Conceived the original idea and statistical analysis, performed additional literature searches, drafted the manuscript, performed additional literature searches, performed data curation and statistical analyses, supervised the project MJW - Collected the data and contributed to laboratory content of the manuscript

FB - Collected the data and contributed to the analysis and data curation

LR - Provided resources, validated methodology and feasibility, supervised the project

$\mathrm{JH}$ - Collected the data and contributed to laboratory content of the manuscript

JBS - Collected the data and contributed to laboratory content of the manuscript

MP — Collected the data and contributed to laboratory content of the manuscript

SB - Collected the data and contributed to laboratory content of the manuscript

VD - Collected the data and contributed to laboratory content of the manuscript

$\mathrm{ACL}$ - Performed data curation and statistical analyses, performed additional literature searches, drafted the manuscript, visualized data presentation, review and editing, supervised the project

All authors approved the final version to be published and agreed to be accountable for all aspects of the work.

The content and view expressed in this article are those of the authors and do not necessarily reflect those of the Government of Canada.

\section{Competing interests}

None.

\section{Acknowledgments}

We thank all participants, the administrators and personnel of the walk-in centres who took care of them and performed the IDN, and the laboratory technologists who performed the SOC-NAATs for this study.

\section{Funding}

This PRONTO study received no private funding. The ID NOW kits were provided in-kind from Health Canada, and human resources were funded by the Ministère de la Santé et des Services sociaux through the budget of each of the three participating institutions.

\section{References}

1. Esbin MN, Whitney ON, Chong S, Maurer A, Darzacq X, Tjian R. Overcoming the bottleneck to widespread testing: a rapid review of nucleic acid testing approaches for COVID-19 detection. RNA 2020;26(7):771-83. DOI PubMed

2. European Centre for Disease Prevention and Control. Diagnostic testing and screening for SARS-CoV-2. Stockholm, Sweden; ECDC: (updated 2021-05-21; accessed 2021-07-21). https://www.ecdc.europa.eu/en/ covid-19/latest-evidence/diagnostic-testing

3. World Health Organization. Laboratory testing for coronavirus disease 2019 (COVID-19) in suspected human cases: interim guidance, 2 March 2020. Geneva (CH): WHO; 2020 (accessed 2021-07-21). https://apps.who.int/iris/ handle/10665/331329

4. Centers for Disease Control and Prevention. Interim Guidelines for Collecting and Handling of Clinical Specimens for COVID-19 Testing. Atlanta, GA: CDC; (updated 2021-02-26; accessed 2021-07-21). https://www.cdc.gov/ coronavirus/2019-ncov/lab/guidelines-clinical-specimens. html

5. Pettengill MA, McAdam AJ. Can We Test Our Way Out of the COVID-19 Pandemic? J Clin Microbiol 2020;58(11):e02225-20. DOI PubMed

6. Weissleder R, Lee $\mathrm{H}$, Ko J, Pittet MJ. COVID-19 diagnostics in context. Sci Transl Med 2020;12(546):eabc1931. DO

7. Larremore DB, Wilder B, Lester E, Shehata S, Burke JM, Hay JA, Tambe M, Mina MJ, Parker R. Test sensitivity is secondary to frequency and turnaround time for COVID-19 screening. Sci Adv 2021;7(1):eabd5393. DOI PubMed

8. Mina MJ, Parker R, Larremore DB. Rethinking Covid-19 Test Sensitivity - A Strategy for Containment. N Engl J Med 2020;383(22):e120. DOI PubMed

9. Adhikari SP, Meng S, Wu YJ, Mao YP, Ye RX, Wang QZ, Sun C, Sylvia S, Rozelle S, Raat H, Zhou H. Epidemiology, causes, clinical manifestation and diagnosis, prevention and control of coronavirus disease (COVID-19) during the early outbreak period: a scoping review. Infect Dis Poverty 2020;9(1):29. DOl PubMed 
10. Hellewell J, Abbott $\mathrm{S}$, Gimma A, Bosse NI, Jarvis $\mathrm{Cl}$, Russell TW, Munday JD, Kucharski AJ, Edmunds WJ, Funk S, Eggo RM; Centre for the Mathematical Modelling of Infectious Diseases COVID-19 Working Group. Feasibility of controlling COVID-19 outbreaks by isolation of cases and contacts. Lancet Glob Health 2020;8(4):e488-96.

DOI PubMed

11. Harrington A, Cox B, Snowdon J, Bakst J, Ley E, Grajales P,Maggiore J, Kahn S. Comparison of Abbott ID Now and Abbott m2000 Methods for the Detection of SARS-CoV-2 from Nasopharyngeal and Nasal Swabs from Symptomatic Patients. J Clin Microbiol 2020;58(8):e0079820. DOI PubMed

12. Smithgall MC, Scherberkova I, Whittier S, Green DA. Comparison of Cepheid Xpert Xpress and Abbott ID Now to Roche cobas for the Rapid Detection of SARS-CoV-2. J Clin Virol 2020;128:104428. DOI PubMed

13. Basu A, Zinger T, Inglima K, Woo KM, Atie O, Yurasits L, See B, Aguero-Rosenfeld ME. Performance of Abbott ID Now COVID-19 Rapid Nucleic Acid Amplification Test Using Nasopharyngeal Swabs Transported in Viral Transport Media and Dry Nasal Swabs in a New York City Academic Institution. J Clin Microbiol 2020;58(8):e01136-20. DOI PubMed

14. Lephart PR, Bachman MA, LeBar W, McClellan S, Barron K, Schroeder L, Newton DW. Comparative study of four SARS-CoV-2 Nucleic Acid Amplification Test (NAAT) platforms demonstrates that ID NOW performance is impaired substantially by patient and specimen type. Diagn Microbiol Infect Dis 2021;99(1):115200. DOI PubMed

15. Mitchell SL, George KS. Evaluation of the COVID19 ID NOW EUA assay. J Clin Virol 2020;128:104429. DOI PubMed

16. Canadian Public Health Laboratory Network and the Canadian Society of Clinical Chemists. Interim guidance on the use of the Abbott ID NOW'TM instrument and COVID-19 assay. Can Commun Dis Rep 2020;46(11-12):422-6. DOI PubMed

17. Rhoads DD, Cherian SS, Roman K, Stempak LM, Schmotzer CL, Sadri N. Comparison of Abbott ID Now, DiaSorin Simplexa, and CDC FDA Emergency Use Authorization Methods for the Detection of SARS-CoV-2 from Nasopharyngeal and Nasal Swabs from Individuals Diagnosed with COVID-19. J Clin Microbiol 2020;58(8):e00760-20. DOI PubMed

18. Gobeille Paré S, Bestman-Smith J, Fafard J, Doualla-Bell F, Jacob-Wagner M, Lavallée $C$, Charest $H$, Beauchemin $S$, Coutlée F, Dumaresq J, Busque L, St-Hilaire M, Lépine G, Boucher V, Desforges M, Goupil-Sormany I, Labbé AC; G-SPIT study group. Natural spring water gargle samples as an alternative to nasopharyngeal swabs for SARS-CoV-2 detection using a laboratory-developed test. J Med Virol 2021. DOI PubMed

19. Dumaresq J, Coutlée F, Dufresne PJ, Longtin J, Fafard J, Bestman-Smith J, Bergevin $M$, Vallières $E$, Desforges $M$, Labbé AC. Natural spring water gargle and direct RT-PCR for the diagnosis of COVID-19 (COVID-SPRING study). $\mathrm{J}$ Clin Virol 2021;144:104995. DOI PubMed
20. Corman VM, Landt O, Kaiser M, Molenkamp R, Meijer A, Chu DK, Bleicker T, Brünink S, Schneider J, Schmidt ML, Mulders DG, Haagmans BL, van der Veer B, van den Brink $S$, Wijsman L, Goderski G, Romette JL, Ellis J, Zambon M, Peiris M, Goossens H, Reusken C, Koopmans MP, Drosten C. Detection of 2019 novel coronavirus (2019-nCoV) by real-time RT-PCR. Euro Surveill 2020;25(3):2000045. DOI PubMed

21. Fleiss JL. Statistical Methods for Rates and Proportions. $2^{\text {nd }}$ ed. New York: John Wiley \& Sons; 1981.

22. Lee J, Song JU. Diagnostic accuracy of the Cepheid Xpert Xpress and the Abbott ID NOW assay for rapid detection of SARS-CoV-2: A systematic review and meta-analysis. J Med Virol 2021;93(7):4523-31. DOI PubMed

23. Subsoontorn $P$, Lohitnavy $M$, Kongkaew $C$. The diagnostic accuracy of isothermal nucleic acid point-of-care tests for human coronaviruses: A systematic review and meta-analysis. Sci Rep 2020;10(1):22349. DOI PubMed

24. Tu YP, lqbal J, O'Leary T. Sensitivity of ID NOW and RT-PCR for detection of SARS-CoV-2 in an ambulatory population. eLife 2021;10:e65726. DOI PubMed

25. Ghofrani M, Casas MT, Pelz RK, Kroll C, Blum N, Foster SD. Performance characteristics of the ID NOW COVID-19 assay: A regional health care system experience. medRxiv. 2020; 2020.06.03.20116327v1. https://www.medrxiv.org/content/ medrxiv/early/2020/06/05/2020.06.03.20116327.full.pdf

26. Leong KW, Law TL, Saiful AS. Kang, Woo, Chow, Yong ZL. Excellent negative predictive value (99.8\%) of two rapid molecular COVID-19 tests compared to conventional RT-PCR for SARS-CoV-2 (COVID-19) in 2,011 tests performed in a single centre. medRxiv. 2021; 2021.06.20.21258392v1. https://www.medrxiv.org/content/medrxiv/ear ly/2021/06/21/2021.06.20.21258392.full.pdf

27. Comer S, Fisk D. An Extended Laboratory Validation Study and Comparative Performance Evaluation of the Abbott ID NOW'TM COVID-19 Assay in a Coastal California Tertiary Care Medical Center. medRxiv. 2020; 2020.06.14.20130518. https://www.medrxiv.org/content/medrxiv/ear ly/2020/06/16/2020.06.14.20130518.full.pdf

28. Stokes W, Berenger BM, Singh T, Adeghe I, Schneider A, Portnoy D, King T, Scott B, Pabbaraju K. shokoples S, Wong AA, Gill K, Turnbull L, Hu J, Tipples G. Acceptable Performance of the Abbott ID NOW Among Symptomatic Individuals with Confirmed COVID-19. medRxiv. 2020; 2020.12.24.20248786. https://www.medrxiv.org/content/ medrxiv/early/2020/12/30/2020.12.24.20248786.full.pdf

29. Balayla J, Lasry A, Gil Y, Volodarsky-Perel A. Prevalence Threshold and Temporal Interpretation of Screening Tests: The Example of the SARS-CoV-2 (COVID-19) Pandemic. medRxiv. 2020; 2020.05.17.20104927. https://www.medrxiv.org/content/medrxiv/ear ly/2020/05/22/2020.05.17.20104927.full.pdf 
30. Burnes LE, Clark ST, Sheldrake E, Faheem A, Poon BP, Christie-Holmes N, Finlay L, Kandel C, Phan M, Frankland C, Lau T, Gubbay JB, Corbeil A, Katz K, Kozak RA. One swab, two tests: validation of dual SARS-CoV-2 testing on the Abbott ID NOW'M . J Clin Virol 2021;141:104896.

DOI PubMed

31. LeBlanc JJ, Heinstein C, MacDonald J, Pettipas J, Hatchette TF, Patriquin G. A combined oropharyngeal/nares swab is a suitable alternative to nasopharyngeal swabs for the detection of SARS-CoV-2. J Clin Virol 2020;128:104442. DOI PubMed

32. Longtin $Y$, Charest $H$, Quach $C$, Savard $P$, Baz M, Boivin G, Farfard J, Villeneuve J, Roger M, De Serres G. Infectivity of healthcare workers diagnosed with coronavirus disease 2019 (COVID-19) approximately 2 weeks after onset of symptoms: A cross-sectional study. Infect Control Hosp Epidemiol 2021;11:1-3. DOI PubMed

33. Manzulli V, Scioscia G, Giganti G, Capobianchi MR, Lacedonia D, Pace L, Cipolletta D, Tondo P, De Nittis R, Rondinone V, Serrecchia L, Parisi A, Galante D, Lo Caputo S, Santantonio TA, Moschetta D, Dattoli V, Fasanella A, Foschino Barbaro MP. Real Time PCR and Culture-Based Virus Isolation Test in Clinically Recovered Patients: Is the Subject Still Infectious for SARS-CoV2? J Clin Med 2021;10(2):309. DOI PubMed

34. Bullard J, Dust K, Funk D, Strong JE, Alexander D, Garnett L, Boodman C, Bello A, Hedley A, Schiffman Z, Doan K, Bastien N, Li Y, Van Caeseele PG, Poliquin G. Predicting infectious SARS-CoV-2 from diagnostic samples. Clin Infect Dis 2020;1(10):2663-6. DOl PubMed
35. Krause E, Puyskens A, Bourquain D, Brinkmann A, Biere B, Schaade $L$, Michel J, Nitsche A. Sensitive on-site detection of SARS-CoV-2 by ID NOW COVID-19. Mol Cell Probes 2021;58:101742. DOI PubMed

36. Sepulveda JL, Abdulbaki R, Sands Z, Codoy M, Mendoza S, Isaacson N, Kochar O, Keiser J, Haile-Mariam T, Meltzer AC, Mores CN, Sepulveda AR. Performance of the Abbott ID NOW rapid SARS-CoV-2 amplification assay in relation to nasopharyngeal viral RNA loads. J Clin Virol 2021;140:104843. DOI PubMed

37. Zimmer R. Delays in testing as a source of COVID-19 false-negative results. Can Fam Physician 2020;66(12):e298-301. DOI PubMed

38. Woloshin S, Patel N, Kesselheim AS. False Negative Tests for SARS-CoV-2 Infection - Challenges and Implications. N Engl J Med 2020;383(6):e38. DOl PubMed

39. Paré I. $41 \%$ of people with symptoms don't get tested. Le Devoir. 2021, 29 January; Sect. Health. https://www.ledevoir. com/societe/sante/594260/coronavirus-les-quebecois-pas-sienclins-au-depistage

40. Layfield LJ, Camp S, Bowers K, Miller DC. SARS-CoV-2 detection by reverse transcriptase polymerase chain reaction testing: analysis of false positive results and recommendations for quality control measures. Pathol Res Pract 2021;225:153579. DOI PubMed 